Rev. Hist., $\mathrm{N}^{\circ} 27$, vol. 2, Julio-Diciembre 2020: 9-36

ISSN 0717-8832

https://doi.org/10.29393/RH27-10SHSC20010

\title{
Sistemas hidro-sociales, gestión estatal y legalización del rol de privados: efectos de la sequía y la lucha por el agua a inicios del siglo XX en la Provincia de Santiago*
}

\author{
Hydro-social systems, state management and legalization of the private role: effects \\ of the drought and the struggle of water in the early twentieth century in Provincia de \\ Santiago
}

Sebastián Castillo: https://orcid.org/0000-0002-5402-9584**
Pablo Camus: https://orcid.org/0000-0002-9705-6320***

\section{RESUMEN}

Este artículo estudia la sequía que afectó a la Provincia de Santiago durante la segunda mitad de la década de 1900. A partir del análisis de documentos del Fondo de Intendencia de Santiago del Archivo Nacional Histórico, prensa escrita de la época y de bibliografía secundaria especializada, se estudian los factores que incidieron en la disminución de agua disponible y las respuestas estatales ante este desafío hídrico. Se plantea que el Estado buscó ejercer un mayor control sobre los ríos de la Provincia, junto con legalizar la administración de las asociaciones de canalistas. En consecuencia, esta sequía, influenciada por factores naturales y humanos, fue una oportunidad para adoptar medidas privatizadoras del agua.

Palabras clave: Sistemas hidro-sociales, sequía, Provincia de Santiago, Estado chileno, asociaciones de canalistas, acumulación por desposesión.

\section{ABSTRACT}

This paper studies the drought that affected the province de Santiago during the second half of the 1900s. Through the analysis of official documents from the National Historical Archive of Chile, written press and specialized secondary bibliography, we study the factors that affected the decrease of available water and state responses to this environmental challenge. We propose that the State sought to exercise greater control over the rivers of the province, along with legalizing the administration of channels to private associations. Consequently, this drought, influenced by natural and human factors, was an opportunity to adopt water privatization measures.

Keywords: Hydro-social systems, drought, Province of Santiago, Chilean state, channel associations, accumulation by dispossession.

Recibido: marzo 2020

Aceptado: septiembre 2020

\footnotetext{
${ }^{*}$ Artículo elaborado en el marco del Proyecto FONDECYT regular no 1180537, titulado “¿Despotismo hidráulico? Irrigación, organización social y conflictos por el agua en una sociedad en transición al capitalismo. Valle central de Chile. 1856-1914".

** Licenciado en Historia, Pontificia Universidad Católica, Chile. E-mail: secastil@uc.cl

*** Doctor en Historia, Pontificia Universidad Católica de Chile. Académico Instituto de Historia, Pontificia Universidad Católica de Chile, Chile. E-mail: pcamusg@uc.cl
} 


\section{Introducción}

El agua ha permitido el desarrollo de sociedades y el despliegue de actividades humanas cada vez más diversas y complejas. La comprensión de su abundancia o escasez, según un momento y espacio histórico, ha trascendido los ciclos hidrológicos naturales que enfatizan variables meteorológicas o geográficas. A partir de aquello, ha emergido un enfoque que ha considerado el agua como un constructo socioecológico, permitiendo comprenderla a partir de su contexto social, a diferencia de estudios convencionales que han abordado a la sociedad y el agua como dos entes distintos que interactúan entre ellos. Este tratamiento implica comprender la naturaleza, universalidad y las dimensiones ecológica, social y cultural del agua ${ }^{1}$, variables indispensables para entender los usos, cambios, transformaciones, concepciones e intereses que giran en torno al recurso hídrico.

Uno de los principales aportes del enfoque socioecológico del agua es la categoría "sistema hidro-social". Fue concebida a partir del entendimiento multidimensional del manejo del recurso hídrico por parte de la sociedad, y de la premisa que tanto el agua como la sociedad se construyen y reconstruyen uno al otro en el tiempo y espacio ${ }^{2}$. El concepto presenta tres categorías de análisis que refuerzan las múltiples dimensiones de las relaciones entre naturaleza y sociedad. La primera concierne la forma física y el comportamiento del agua, considerándolos como parte central de cualquier ecosistema; la segunda categoría engloba las modificaciones de los flujos de agua hechas por el hombre y los artefactos creados por él para aprovecharla; mientras que la tercera es la dimensión conceptual e institucional de los sistemas de agua ${ }^{3}$. Estas dimensiones son relevantes para la historiografía ambiental y chilena, pues ofrecen una perspectiva interesante para estudiar cuál ha sido rol del Estado en el manejo de recursos hídricos y qué intereses económicos y sociales de las elites han subyacido a la expansión de la red de agua de la zona metropolitana del país.

La dimensión conceptual e institucional del sistema hidro-social propuesta por Tvedt remite a los efectos de la administración estatal sobre los sistemas de agua. A pesar de críticas posteriores ${ }^{4}$, Karl Wittfogel fue precursor de la idea de que el poder político ha ejercido una fuerte influencia en los sistemas de agua, es decir, que la gestión estatal ha incidido en el

\footnotetext{
${ }^{1}$ Linton, Jamie. 2010. What is water? The history of a modern abstraction, Vancouver, UBC Press.

${ }^{2}$ Linton, Jamie y Budds, Jessica. 2014. "The hydrosocial cicle: Defining and mobilizing a relational-dialectical approach to water", en Geoforum, № 57, Amsterdam, pp. 170-180.

${ }^{3}$ Tvedt, Terje. 2010. "'Water systems', Environmental History and the Deconstruction of Nature", en White Horse Press, № 2, Vol. 15, Cambridgeshire, p. 147.

${ }^{4}$ Arthur Maass y otros autores no comparten la correlación entre estados despóticos y la construcción y operación de sistemas hidro-sociales sugerida por Wittfogel. Plantean que los roles del Estado como árbitro en conflictos entre regantes -especialmente en litigios sobre sistemas hidráulicos en formación-y como constructor de obras hidrosociales, no han creado el despotismo oriental que sugiere Wittfogel. Arthur Maass y Anderson. 1978. ... and the desert shall rejoice: Conflict, growth and justice in arid environments, Cambridge, The MIT Press Offices.
} 
funcionamiento de los sistemas hidro-sociales desplegados en el territorio, repercutiendo directamente en el desarrollo de la sociedad ${ }^{5}$. Uno de los objetivos del estudio de los sistemas hidro-sociales es integrar los procesos biológicos, físicos y sociopolíticos del agua, desentrañando las relaciones complejas entre los flujos de agua y las relaciones de poder ${ }^{6}$. Por lo tanto, la dimensión institucional de los sistemas hidro-sociales hace remitirnos al concepto de poder.

En este sentido, Bourdieu propuso el concepto "poder simbólico" para estudiar la legitimación de la dominación de una clase sobre otra a través de la producción simbólica, la que está sustentada por el poder económico de los grupos dominantes ${ }^{7}$. Asimismo, Gramsci plantea que la clase dirigente dispone del Estado y otros medios para perpetuar su dominación y ejercer su influencia sociocultural y económica sobre la sociedad, lo que define como "hegemonía"s.

En consecuencia, es pertinente explorar los vínculos entre los sistemas de poder, el uso, manejo y distribución del agua y la organización de los sistemas hidro-sociales ${ }^{9}$. A partir del período colonial, el Estado chileno llevó a cabo procesos de comercialización del agua, en los que fue entregando mercedes hídricas a particulares, por lo que la privatización debe ser entendida como parte de una transformación amplia de la gestión del agua ${ }^{10}$. Asimismo, fueron modificadas las relaciones entre la sociedad, su economía y el medioambiente, cambios visibles en actividades extensivas como la agricultura y que han requerido volúmenes importantes de agua para su despliegue. Una de las consecuencias más importantes de los procesos de privatización del agua ha sido el debilitamiento de su noción como bien público o común. Este acaparamiento de derechos de propiedad que otrora eran comunes es definido por David Harvey como "acumulación por desposesión"11.

El objeto de estudio de la presente investigación son las sequías de comienzos del siglo XX en la Provincia de Santiago, junto con sus consecuencias en la gestión del agua y las respuestas estatales durante aquel período de escasez. Si bien se asocia comúnmente a la sequía con una reducción de precipitaciones en una temporada, hay autores que han sugerido considerar sus

\footnotetext{
${ }^{5}$ Wittfogel, Karl. 1966. Despotismo Hidráulico, Madrid, Ediciones Guadarrama.

6 Bakker, Karen. 2003. "A political ecology of water privatization", en Studies in Political Economy, № 70, United Kingdom, pp. 35-58.

${ }^{7}$ Bourdieu, Pierre. 1977. "Sobre el poder simbolico", en Gutiérrez, Alicia. 2000. Intelectuales, política y poder, Buenos Aires, UBA/ Eudeba, pp. 65-73.

${ }^{8}$ Gramsci, Antonio. 1975. Quaderni dal carcere, a cura di Valentino Gerrtana, Torino, Einaudi, en Cortes, Eugenio. 2014. "La hegemonia cultural hoy: la hegemonía como método analítico en los estudios culturales", en Pensamiento Actual, № 22, Vol. 14, Costa Rica.

${ }^{9}$ Swyngedouw, Eric. 2009. "The political economy and political ecology of the hydro-social cycle", en Journal of contemporary water research \& education, № 142, Illinois, pp. 56-60.

${ }^{10}$ Bakker, Karen. 2003, "A political ecology", p. 37.

${ }^{11}$ Harvey, David. 2003. El nuevo imperialismo, Madrid, Ediciones Akal.
} 
factores humanos. Mike Davis define la sequía como un duelo recurrente entre la variabilidad natural de las precipitaciones y las defensas hidráulicas de los agricultores. El autor propone la distinción entre la sequía meteorológica y la hidráulica. La primera es la disminución porcentual en la precipitación anual de un lugar, relacionada con las condiciones naturales de este. Mientras que la segunda incorpora la dimensión productiva, al hacer referencia a la baja disponibilidad de agua de almacenamientos naturales y artificiales para salvar las cosechas sembradas ${ }^{12}$. Davis propone que la sequía hidrológica siempre ha tenido una historia social que sugiere que las sequías más devastadoras del siglo XIX fueron condicionadas por acciones humanas como el abandono de sistemas de riego tradicionales y la falta de inversión estatal en infraestructura para almacenaje de agua ${ }^{13}$. La relevancia del factor humano en el desencadenamiento de sequías es reafirmada por Rolando García, quien plantea que los fenómenos climáticos no son fenómenos por sí mismos, sino que son consecuencia de la reestructuración del medioambiente hecha por el hombre de acuerdo a sus actividades productivas $^{14}$.

El espacio en el que se enmarca este estudio es la Provincia de Santiago, zona metropolitana en la que se concentraba el poder político y económico de Chile incluso desde antes de su conformación como república. Ella abarcaba el valle del río Mapocho y los campos regados por el río Maipo, zona que fue llamada a ser uno de los centros de grandes explotaciones agrícolas, dados sus suelos planos con características idóneas para desarrollar cultivos agrícolas y una variedad de recursos hidrográficos con la que contaba ${ }^{15}$. El marco temporal investigado es la segunda mitad de la década de 1900, años en los que hubo una disminución considerable en la cantidad de aguas lluvias caídas, lo cual repercutió en la disponibilidad hídrica de la provincia.

En base a lo expuesto hasta ahora, el argumento principal que estructura este artículo es que el Estado chileno implementó dos estrategias como respuesta a las sequías sufridas en Santiago desde 1906. La primera fue adoptar un rol vigilante y distribuidor de las aguas de los ríos de la Provincia de Santiago; esto consistió en disponer de recursos humanos y técnicos para controlar sus cauces y bocatomas, así como también repartir el recurso hídrico en períodos de escasez. Mientras que la segunda fue la legalización de la administración de las aguas de los canales por parte de accionistas a través de la aprobación de la ley n2139 sobre asociaciones de canalistas, cuyo principal efecto fue la entrega de la potestad, a dichos conglomerados, de la distribución hídrica y resolución de conflictos dentro de sus márgenes. Así, este estudio aplica dos categorías de análisis de Tvedt, referidas a los cambios hechos en los flujos de agua por

\footnotetext{
12 Davis, Mike. 2000. Late Victorian holocausts: El Niño famines and the making of the Third World, Londres. Verso Books, p. 30.

${ }^{13}$ Ibíd., pp. 30-31.

${ }^{14}$ García, Rolando. 1981. Nature pleads not guilty, Oxford, Pergamon Press, p. 157.

${ }^{15}$ Salazar, Gabriel. 2019. Historia del municipio y la soberanía comunal en Chile (1820-2016), Santiago, Universitaria, p. 311.
} 
actores interesados en ella y a la dimensión institucional del recurso hídrico, particularmente a la gestión pública del agua y a las iniciativas que normaron su uso y consumo privados.

La metodología empleada para elaborar este estudio es de carácter cualitativa y basada en el análisis de fuentes escritas, específicamente de documentos públicos, prensa y bibliografía. En primer lugar, las fuentes escritas oficiales fueron extraídas del Fondo de Intendencia de Santiago del Archivo Histórico Nacional de Chile, que comprenden decretos, comunicaciones entre los Intendentes y autoridades y otros funcionarios de diversas reparticiones estatales, solicitudes y reclamaciones de particulares sobre asuntos hídricos, y evaluación de requerimientos de concesiones de agua, entre otras diligencias. En segundo lugar, se hizo una revisión de fuentes periodísticas de la época, justificándose su pertinencia porque ofrecen un panorama alternativo o complementario al otorgado por las fuentes oficiales. Fueron analizadas algunas noticias sobre la escasez de agua y editoriales acerca de la sequía y su respuesta estatal, así como del rol creciente de privados en la gestión hídrica. Toda esta documentación fue sistematizada en una base de datos y seleccionada a partir de subtemas elaborados a partir de la idea central del estudio. Mientras que, en tercer lugar, se realizó una revisión bibliográfica que le da sustento teórico a nuestra propuesta. Estas fuentes secundarias se refieren al enfoque socioecológico del agua, a los sistemas hidro-sociales y a la noción hidráulica de la sequía, entre otros temas.

La primera parte de este estudio abordará la escasez de precipitaciones que sufrió la Provincia de Santiago, analizando tanto su dimensión meteorológica como sus efectos hidráulicos y productivos, de acuerdo con las categorías de Mike Davis. Los próximos dos apartados han sido elaborados gracias a las dimensiones humana e institucional del agua propuestas por Tedje Tvedt. Se estudiará el aumento del control estatal de las aguas de los ríos de la provincia como respuesta a la sequía, estrategia que, paradójicamente, muestra algunas tensiones y conflictos entre autoridades, y propició que haya habido casos de acumulación por desposesión hechos por particulares. Mientras que la última parte del desarrollo se centra en el consenso político y económico para favorecer la gestión privada de los canales, por medio de la aprobación de la ley $n$ 2139. A través de la dimensión institucional del agua propuesta por Tvedt, descubrimos los actores que alentaron y aprobaron dicho cuerpo legal, pertenecientes al sector hegemónico de la sociedad chilena, de acuerdo con el concepto de Gramsci. Es pertinente analizar la ley de asociaciones de canalistas porque legalizó mecanismos de acumulación por desposesión y reafirmó el poder simbólico de los grandes poseedores de derechos de aguas. Todas las secciones del artículo están articuladas por el enfoque socioecológico del agua, pues comprobaremos que la sequía y la disponibilidad de agua no solo está afecta a factores naturales, sino también a consideraciones económicas, políticas y sociales. 


\section{Factores y efectos de la sequía de la Provincia de Santiago en los albores del siglo XX}

La década de 1900 es un marco temporal que muestra, en menor escala, la realidad impredecible de nuestro país en cuanto a la ocurrencia de precipitaciones, ya que la Provincia de Santiago presentó variabilidad en los niveles de agua caída en aquellos años. Por una parte, el promedio de precipitaciones entre 1900 y 1904 fue de 518 milímetros, con solo uno muy seco y tres años muy lluviosos, uno de ellos el mayor de la historia en la provincia. Mientras que en los años restantes hubo dos años muy secos, uno seco y tan solo uno muy lluvioso, con un promedio de agua caída de 312 milímetros. A partir de 1905 con sus 616 milímetros, el de aguas lluvias fue descendiendo abruptamente, ya que en 1906 bajó más de la mitad con 294 mms; en 1907 cayeron 268 milímetros, y en 1908 y 1909 solo precipitaron 202 y 184 milímetros, respectivamente, siendo, junto con 1903 , los tres años más secos de la década ${ }^{16}$.

A partir de 1908 hubo episodios de desabastecimiento de agua para regadío y consumo humano, intensificados por la merma en la cantidad de agua caída desde 1906. En noviembre de ese año, El Chileno -periódico de Santiago, conservador y defensor de la Iglesia Católicareportó el escenario complejo de la actividad agrícola en la Provincia de Santiago, caracterizado por la pérdida de cosechas, el gran porcentaje de cuadras sin siembras, los ríos y esteros de Lampa y Colina completamente secos, y el aumento drástico en el precio de frutas, verduras y legumbres para la temporada estiva $\left.\right|^{17}$. La Empresa de Agua Potable de Santiago estableció turnos para proveer del vital elemento a la ciudad, "en vista de la escasez de agua por falta de lluvias en el año próximo pasado (sic.) y por el desarrollo enorme que ha tomado el consumo"18. La relevancia de la dotación de agua para las zonas urbanas radicaba en que el estado sanitario de la provincia dependía de ella. Santiago sufrió una suspensión prolongada del servicio de agua corriente de las acequias en junio de 1908, lo que acrecentó el temor del recrudecimiento de infecciones y epidemias en la ciudad. Si bien había un contexto de sequía, La Prensa-periódico de Santiago que circuló entre 1908 y 1910- señaló como su causa directa unas reparaciones de canales hechas por la Sociedad del Canal del Maipo, criticando que el Código de Aguas propiciaba "una verdadera anarquía de reglamento y disposiciones, muchas veces contradictorias, a las cuales es necesario poner definitivo término"19.

\footnotetext{
${ }^{16}$ Oficina Meteorológica de Chile. 1968. Estudio de las precipitaciones en Chile durante 429 años y la sequía del año 1968 , Santiago.

${ }^{17}$ Biblioteca Nacional (BN), “La sequía”. El Chileno. Santiago, 18 de noviembre de 1908, p. 1.

${ }^{18} \mathrm{BN}$, “Agua potable. El establecimiento de turnos". El Diario llustrado. Santiago, 1 de noviembre de 1909, p. 5.

${ }^{19}$ BN, "Santiago sin agua". La Prensa. Santiago, 24 de junio de 1908, p. 1.
} 
Gráfico 1: Precipitaciones sobre la Provincia de Santiago (1898-1911)

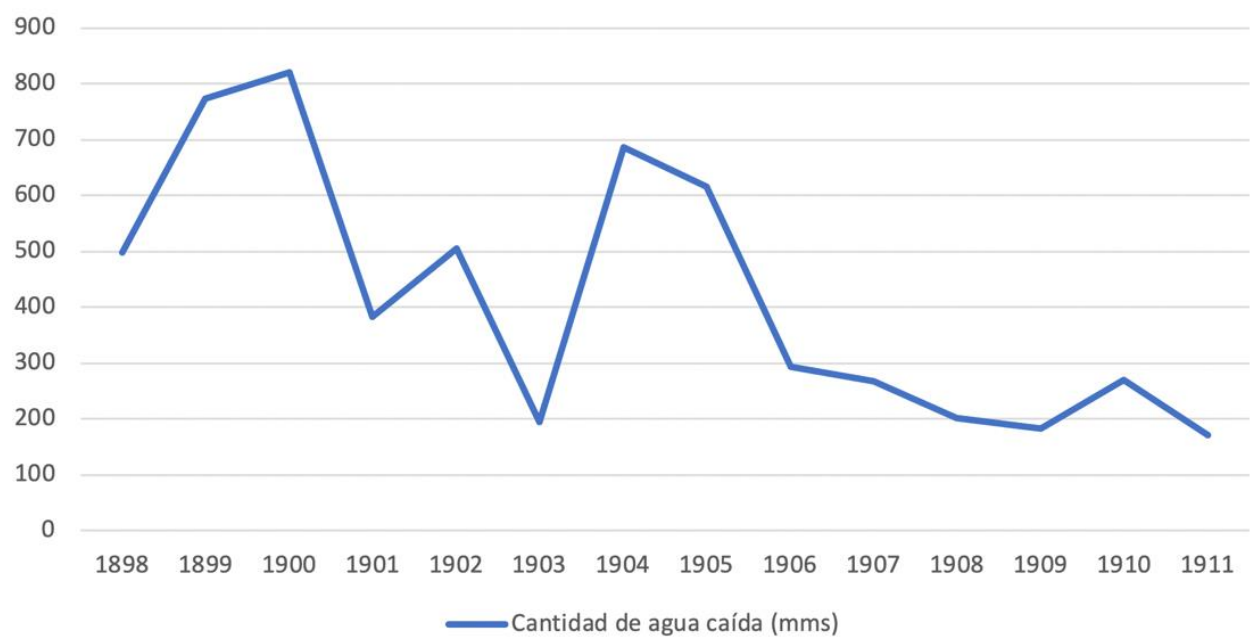

Fuente: elaboración propia a partir de Oficina Meteorológica de Chile. 1968.

Estudio de las precipitaciones en Chile durante 429 años y la sequía del año 1968, Santiago.

La reparación de canales hecha por la Sociedad del Canal del Maipo que dejó sin agua a un Santiago bajo sequía sugiere que la escasez hídrica no se debió solamente a la disminución de aguas Iluvias sufrida en la segunda mitad de la década de 1900. El aprovechamiento indebido de las aguas del río Mapocho fue reportado a la alcaldía de Santiago por un guarda tomas. El 10 de diciembre de 1908, Carlos Bravo denunció que el poco caudal del Mapocho impedía surtir las acequias de la comuna, a causa de particulares que detenían su cauce para regar sus propiedades, pese a que había una orden del juez partidor de aguas que autorizó la extracción de agua solo para consumo de animales ${ }^{20}$. La alcaldía de Santiago informó en marzo de 1909 a la Intendencia que nuevamente había insuficiencia hídrica para la población, a causa de detenciones del flujo del Mapocho por interesados de la zona oriente de la ciudad, por lo que solicitó medidas para "concluir con los abusos de los interesados [...] que ocasionan grandes molestias a la población"21. También hubo robos de agua que fueron denunciados a la Intendencia. Un vecino de Quinta Normal informó a la autoridad provincial que desconocidos robaban su agua de riego y solicitó permiso para poseer un revólver y una carabina en su hogar $^{22}$. Con estos casos expuestos, postulamos que la sequía asociada a la disminución de las

\footnotetext{
${ }^{20}$ Archivo Nacional Histórico, Fondo Intendencia de Santiago, (ANHISAN).Guarda Tomas de Santiago Carlos Bravo a Intendente de Santiago. Santiago, 10 de diciembre de 1908. Vol. 317, s/f.

${ }^{21}$ ANHISAN, Guarda Tomas de Santiago Carlos Bravo a Intendente de Santiago. Santiago, 3 de marzo de 1909. Vol. $326, \mathrm{~s} / \mathrm{f}$.

${ }^{22}$ ANHISAN Guarda Tomas de Santiago Carlos Bravo a Intendente de Santiago Santiago, 7 de abril de 1908., Vol. 327, s/f.
} 
precipitaciones entre 1906 y 1909, habría repercutido en la disponibilidad de agua y visibilizaría el despojo hídrico hecho por grandes propietarios.

El requerimiento del propietario de Quinta Normal para disuadir a quienes robaban su agua de riego muestra uno de los efectos de la escasez hídrica en la Provincia de Santiago en el período estudiado: la violencia como mecanismo de resolución de conflictos hídricos. Un caso ilustrativo fue protagonizado por los agricultores Ignacio Molina y Elías Contreras en Buin, Departamento del Maipo. Ambos predios se abastecían del agua del canal de la Quinta; Molina obtuvo el permiso del dueño del canal para usar el agua, mientras que Contreras lo consiguió, al mismo tiempo, gracias al administrador del propietario. Los agricultores usaron sus revólveres y resultaron seriamente heridos ${ }^{23}$. La no presencia permanente de una autoridad o institución que vigilase y distribuyese el agua en tiempos de escasez, derivó en que particulares utilizaran la fuerza para acceder al vital elemento. El Chileno publicó una editorial titulada "La lucha por el agua" en la que reseñó la emergencia de numerosos litigios judiciales por el acceso hídrico sin resoluciones satisfactorias para las partes, habiendo "en todas partes, en los campos y en las ciudades una encarnizada lucha para obtener el agua". El periódico señaló que "han sido inútiles las protestas dirigidas a las autoridades locales", por lo que algunas personas "han hecho una última y desesperada tentativa, dirigiéndose a S.E. el Presidente de la República, a quien piden la adopción de medidas urgentes y enérgicas" ${ }^{24}$.

La Alcaldía de Santiago reconoció el estado de emergencia hídrico y alcanzó acuerdos con actores privados para asegurar la dotación de agua en la Provincia de Santiago. El 26 de agosto de 1908 se reunieron el alcalde de Santiago con miembros de la Junta de Vigilancia del río Mapocho en dicho municipio. Una vez que se decidió buscar nuevas fuentes hídricas para satisfacer los intereses locales ante la insuficiencia del caudal del Mapocho, los presentes determinaron encomendar al juez de agua repartir equitativamente el recurso hídrico a los comuneros, dotar a dicha autoridad de los elementos necesarios para su labor, y entregar al guarda tomas municipal el agua que correspondiese para la ciudad ${ }^{25}$. En consecuencia, la Alcaldía de Santiago, a través del mandato al juez de aguas, buscaba mayor protagonismo en la distribución y el control de las aguas del río Mapocho, dado que una sección de este pasaba por la comuna. Ante esta participación activa que buscaba proyectar la autoridad local, cabe preguntarse cómo gestionó el Estado la vigilancia del agua en aquellos años con bajas precipitaciones, y cuál fue el rol de las autoridades provinciales, judiciales y comunales.

\footnotetext{
${ }^{23}$ BN, "El agua disputada a balazos". El Chileno. Santiago, 17 de noviembre de 1908, p. 1.

${ }^{24}$ BN, "La lucha por el agua. Problema de actualidad". El Chileno. Santiago, 16 de diciembre de 1908, p. 1.

${ }^{25}$ BN, "La cuestión del agua. La reunión de ayer". El Diario Ilustrado. Santiago, 27 de agosto de 1908, p. 4.
} 


\section{Rol vigilante y distribuidor de aguas de ríos de la Alcaldía e Intendencia de Santiago.}

Desde que Chile se convirtió en una república independiente a fines de la década de 1810, el Estado ha desplegado la administración del territorio a través de la descentralización y desconcentración, conceptos que engloban a todas las instituciones y autoridades que forman parte del aparato burocrático. El Ministerio de Industria y Obras Públicas, la Intendencia de Santiago y la Alcaldía de Santiago fueron las reparticiones públicas con mayor injerencia en la administración estatal sobre los ríos de la provincia, encargadas de evaluar solicitudes de mercedes de aguas, revisar el estado de la infraestructura hídrica, buscar nuevas fuentes de agua y repartir y vigilar las aguas del río Mapocho.

A pesar de la menor cantidad de agua caída en la Provincia de Santiago entre 1906 y 1909, el Ministerio de Industria y Obras Públicas continuó otorgando mercedes de agua a particulares para fines variados como regar sembrados o generar fuerza motriz ${ }^{26}$. Sin embargo, la disponibilidad limitada el recurso hídrico fue un argumento esgrimido por la autoridad para cuestionar requerimientos de mercedes que habrían puesto en riesgo el abastecimiento general de la población. La Intendencia de Santiago recibió una solicitud de concesión de sesenta regadores que deseaban extraer agua desde el Zanjón de la Aguada para regar el fundo El Coronel. Se consideró que su aprobación disminuiría el caudal del zanjón y perjudicaría a terceros con derechos adquiridos más abajo, junto con criticarse el valor elevado de la concesión ${ }^{27}$. En definitiva, el bienestar colectivo por sobre el interés particular fue, al menos, considerado en la evaluación de las solicitudes de mercedes de agua durante aquel período de sequía.

Para el Estado fue fundamental revisar la infraestructura hídrica de la Provincia de Santiago, pues tanto la calidad como la cualidad de los ductos incidían en la distribución del agua. El Intendente de Santiago, con motivo del uso indebido de algunos canalistas de las aguas del Mapocho, planteó en 1909 que toda medida tendiente a salvaguardar los derechos de agua de la población no tendría resultados, dado que las tomas de canales estaban en pésimo estado y habían sido hechas con piedras y otros materiales ligeros. La autoridad provincial sugirió la colocación de medidores de agua en todos los canales derivados del río Mapocho, tal y como en aquellos derivados del río Maipo ${ }^{28}$. Ese mismo año Guillermo Illanes, ingeniero jefe de la Inspección General de Hidráulica, elaboró un informe solicitado por el Gobierno Central para examinar las causas de la escasez de agua en Santiago. Una de ellas fue la capacidad excesiva de las cañerías matrices, muy mayor al caudal de agua que transportaban, y sus disposiciones

\footnotetext{
${ }^{26}$ Algunos decretos de concesiones que permiten sostener aquella afirmación son: ANHISAN Santiago, 2 de marzo de 1907., Vol. 327, s/f.; Santiago, 27 de noviembre de 1908. ANHISAN, Vol. 317, s/f.; Santiago, 3 de diciembre de 1908. ANHISAN, Vol. 327, s/f.; Santiago, 22 de septiembre de 1909. ANHISAN, Vol. 332, s/f.

${ }^{27}$ ANHISAN Ministro de Industria a Intendente de Santiago. Santiago, 6 de febrero de 1907., Vol. 307, s/f.

${ }^{28}$ ANHISAN Intendente de Santiago a Ministro del Interior. Santiago, 12 de febrero de 1909., Vol. 339, s/f.
} 
defectuosas, lo cual contribuyó a la cantidad deficiente de agua para la población ${ }^{29}$. En suma, otro efecto de la sequía de la segunda mitad de la década de 1900 fue la revisión de la infraestructura hídrica que conducía el agua en la provincia, es decir, ese período de bajas precipitaciones develó el real funcionamiento de los ríos, canales, cañerías y tomas que conformaban el sistema hidro-social de la zona metropolitana del país.

El informe de Guillermo Illanes adujo otro problema derivado de la escasez hídrica que experimentaba Santiago: la dotación de agua por persona era insuficiente ${ }^{30}$. Para subsanarlo, el Estado se encargó de la búsqueda de nuevas fuentes hídricas. La Intendencia de Santiago creyó conveniente en 1909 la realización de estudios para aprovechar "las aguas que en gran cantidad se escurren bajo la superficie del suelo, especialmente de la parte Oriente de la ciudad, valiéndose para ello de cañerías de captación" ${ }^{\prime 31}$. Cabe destacar que, hasta el período estudiado, la captación de aguas subterráneas no era una actividad masificada ni mucho menos regulada legalmente por el Estado. En octubre de 1908, El Chileno se refirió a estas aguas "que corren a tajo abierto por la ciudad", tan necesarias por la población que cultivaba sus frutas y verduras bajo altas temperaturas y escasez hídrica. El periódico criticó la falta de regulación que beneficiaba al gran propietario, quien "se adueña de las aguas corrientes, valiéndose de influencia y derechos establecidos en la fortuna o en la vista gorda de las autoridades, demasiado complacientes con los poderosos"32. En definitiva, la carencia de un marco regulatorio es una muestra del "dejar hacer" del Estado, lo que habría propiciado una acumulación por desposesión que perjudicaba a la población en general y a los pequeños agricultores en particular, pues los despojos de aguas hechos por grandes propietarios disminuían el caudal disponible para el resto de los actores.

Este rol pasivo del Estado ante algunos despojos de aguas hechos por particulares contrasta con su principal misión hídrica en la Provincia de Santiago durante la sequía de la segunda mitad de 1900, que fue vigilar las aguas del río Mapocho. La relevancia por controlar su caudal hídrico quedó reflejada en la creación del cargo de fiscalizador de aguas del río Mapocho. El Intendente de Santiago Pablo Urzúa solicitó su nombramiento en diciembre de 1908 al Ministerio de Industria y Obras Públicas; una vez aceptado por dicha cartera, el gobierno provincial nombró al comisario de policía José Santiago Melo como fiscalizador de aguas, "quien se ceñirá a las órdenes de la Intendencia, sobre este particular, de acuerdo con el artículo 836 del Código de

\footnotetext{
${ }^{29}$ BN, “La escasez de agua. Análisis de sus causas". El Chileno. Santiago, 10 de febrero de 1909, p. 1.

${ }^{30}$ Idem.

${ }^{31}$ ANHISAN Intendente de Santiago a Ministro del Interior. Santiago, 26 de agosto de 1909., Vol. 340, s/f.

$32 \mathrm{BN}$, “El agua en los suburbios. La necesidad de colocarla a turno". El Chileno. Santiago, 27 de octubre de 1908, p. 2.
} 
Procedimiento Civil”33 de $1902^{34}$. La Intendencia de Santiago fundamentó la necesidad de contar con un fiscalizador ante las quejas de agricultores e industriales que sufrían despojos de aguas, para así evitar incidentes entre comuneros por las distribuciones hídricas. Según la autoridad, "las aguas del río Mapocho son suficientes para llenar las necesidades de la ciudad y de los fundos a que se encuentran destinadas; pero es necesario ejercer una severa vigilancia policial para evitar que los interesados inescrupulosos continúen cometiendo abusos"35. En otras palabras, el Estado atribuyó como causa principal de la escasez hídrica que sufrió Santiago al aprovechamiento de aguas hecho por particulares, no a la disminución drástica de precipitaciones vividas entre 1906 y 1909. Esto reafirma la hipótesis que la falta de agua en la Provincia de Santiago en la segunda mitad de la década de 1900 no obedeció solo ni principalmente a factores naturales.

Las labores iniciales hechas por José Melo en el río Mapocho respondieron a la misión del Estado, a través de la Intendencia de Santiago, de fiscalizar el flujo de sus aguas. Entre ellas se encontró la vigilancia permanente del Mapocho y sus tomas, por medio de comisiones compuestas por oficiales y guardianes de la policía designados por la Intendencia de Santiago. El objetivo era "salvaguardar los derechos de agua que la ciudad de Santiago tiene en el río" ${ }^{36}$. El cuidado de tales derechos también implicó la disponibilidad de Melo de recursos, personal e implementos para ejecutar obras en el lecho del río o bocatomas de sus canales, como el retiro de un cierre de alambre hecho por Moisés Errázuriz en el lecho del Mapocho que colindaba con su propiedad ${ }^{37}$. El fiscalizador Melo también inspeccionaba el río y sus tomas ante avisos de escasez de agua, denuncios hechos ante las autoridades o solicitudes de la Intendencia de Santiago, tal y como ocurrió en julio de 1910 ante la ejecución de unas obras de relleno en el lecho del río hechas por propietarios riberanos ${ }^{38}$, o la revisión realizada en marzo de 1910 del estado de la defensa del costado sur del río Mapocho en el sector oriente de Santiago, ordenada por la Intendencia ${ }^{39}$. Las funciones realizadas por José Santiago Melo demuestran que la Intendencia de Santiago deseó ejercer un control lo más estricto posible del Mapocho, a través

\footnotetext{
${ }^{33}$ BN, "Fiscalizador de aguas". El Chileno. Santiago, 30 de diciembre de 1908, p. 2.

${ }^{34} \mathrm{El}$ artículo 836 del Código de Procedimiento Civil de 1902 dictó que, a la autoridad administrativa en materia de policía y concesión de mercedes de aguas, le incumbía facilitar auxilios necesarios para el desempeño de los repartidores de aguas. Además, los dueños de fundos en que se hiciese distribución de agua, no podían impedir el ingreso al repartidor para que desempeñase sus funciones.

${ }^{35}$ ANHISAN "Sobre nombramiento encargado reparto aguas río Mapocho". Santiago, 12 de febrero de 1909., Vol. $339, \mathrm{~s} / \mathrm{f}$.

${ }^{36}$ Idem.

${ }^{37}$ ANHISAN, Intendente de Santiago a Ministro de Industria y Obras Públicas. Santiago, 20 de octubre de 1910. Vol. $358, \mathrm{~s} / \mathrm{f}$.

${ }^{38}$ Idem.

39 "ANHISAN, Remite informe delegado reparto aguas río Mapocho relacionado con defensa en lado sur al oriente de la ciudad". Santiago, 4 de marzo de 1910. Vol. 357, s/f.
} 
de su vigilancia constante e inspección periódica ante cualquier atisbo de anormalidad en sus flujos de agua.

La Intendencia de Santiago, a través de su fiscalizador, no tan solo se encargó de la observación permanente del río Mapocho y sus afluentes. A partir de enero de 1910, dicha institución provincial impuso la distribución de sus aguas por medio de la ampliación de las atribuciones de José Melo, quien pasó a ser Delegado Fiscal en el reparto de las aguas de Santiago. El gobierno provincial fundamentó el nuevo cargo de Melo con un argumento muy similar al esgrimido a fines de 1908 cuando solicitó al Ministerio de Industria y Obras Públicas su nombramiento: "numerosos propietarios de la parte oriente se apropian de mayor caudal de agua de aquel que les corresponde de acuerdo con sus títulos o mercedes, con perjuicio evidente para los intereses de la ciudad"40. Ante el despojo hecho por particulares que atentaba con la provisión de la ciudad, la autoridad decidió adoptar una estrategia más activa que derivó tanto en la vigilancia del río y sus tomas ya realizada anteriormente, como en la modificación de la infraestructura hídrica existente. El Intendente Pablo Urzúa facultó a José Melo, en caso necesario, para alterar las bocatomas de los canales o variar su ubicación. Asimismo, la Intendencia puso a disposición del delegado fiscal el uso de la fuerza pública en caso de requerirlo y ordenó a Melo que diera cuenta a la institución de sus medidas adoptadas y dificultades que debiese sobrellevar. Estos elementos reflejan el dominio que el Estado buscó ejercer sobre el principal río de la Provincia de Santiago, pues garantizar el reparto de agua fue mucho más allá del control de su flujo de agua.

Como se ha visto hasta aquí, tanto la Alcaldía como la Intendencia de Santiago, en cuanto instituciones del Estado, desplegaron estrategias por separado para vigilar e intentar controlar el río Mapocho y sus tomas durante aquellos años de sequía. En consecuencia, es pertinente preguntarse si aquello provocó conflictos entre ellas, y si existieron diferencias entre la Intendencia de Santiago y otras instituciones estatales o actores particulares debido a la labor ejercida por el Delegado Fiscal José Melo.

\section{Conflictos derivados del control estatal sobre los ríos de la provincia}

La sequía que afectó a la Provincia de Santiago en la segunda mitad de la década de 1900, además de visibilizar el estado de los sistemas de agua y los despojos efectuados por particulares, también desencadenó conflictos entre funcionarios del Estado y actores particulares que vieron vulnerados sus derechos de aguas, así como también entre instituciones estatales que aspiraban repartir el recurso hídrico. La Intendencia de Santiago fue cuestionada

\footnotetext{
${ }^{40}$ ANHISAN Intendente de Santiago a Delegado de la Intendencia en el reparto de aguas del río Mapocho. Santiago, 5 de enero de 1910., Vol. 361, s/f.
} 
debido al cargo y atribuciones del Delegado Fiscal José Melo como repartidor de aguas del río Mapocho.

La función repartidora de José Melo fue reprobada por propietarios con derechos de aguas que, aparentemente, no podían ejercer sus derechos de extracción. Una estrategia de ellos fue denunciar aquellas irregularidades a los tribunales de justicia. Segundo Gana y Aurelio González interpusieron una querella de amparo contra el Fisco y el señor José Melo, pues en abril de 1910 la fuerza pública les impidió extraer aguas para regar sus fundos ubicados en la Recoleta Dominica. Los propietarios perjudicados por la actuación estatal exigieron la no perturbación de la posesión hídrica, es decir, ejercer su derecho de extracción de aguas sin impedimentos. Los guardianes de la policía replicaron que estaban cumpliendo órdenes del señor Melo, quien "tiene instrucción del Gobierno para impedir que los comuneros hagan uso del derecho que les corresponde a las aguas del río para aumentar el caudal de las que corresponden a la Municipalidad y a algunos dueños de molino que son comuneros en ella"11. Considerando las declaraciones de la policía recogidas por los canalistas demandantes, se visibilizó la justificación principal del gobierno provincial para ejercer dominio sobre las aguas del río Mapocho, que fue la salvaguardia del bienestar general de la población por sobre los intereses individuales. Sin embargo, esto quedaría en entredicho porque, de acuerdo a Gana y González, la Intendencia impidió la extracción de aguas de los canalistas para aumentar su disponibilidad y fuesen aprovechadas por dueños de molinos, quienes también eran actores particulares.

De esta manera, el argumento de la protección del bienestar general hecho por el Estado para controlar las aguas de los ríos de la Provincia de Santiago podría haber tratado de ocultar acumulaciones por desposesión hechas por otros propietarios. Otro caso que brinda antecedentes sobre esta problemática ocurrió en febrero de 1910. Trescientos dueños de propiedades agrícolas con mercedes de aguas en los ríos Mapocho y Maipo denunciaron la desposesión del usufructo que el Fisco les había concedido. Ellos emplearon una estrategia distinta a la seguida por Segundo Gana y Aurelio González, pues expusieron sus casos ante el Senado de la República gracias a gestiones hechas por el Senador José Balmaceda. Los propietarios también culparon al Delegado Fiscal José Melo de tomar las aguas del Mapocho y Maipo para la ciudad, perjudicando a poseedores de derechos de aguas que no podían sembrar en sus campos ${ }^{42}$. Expuestos los casos de los dos párrafos anteriores, se determina que el conflicto entre el Estado y particulares fue entendido, discursivamente, como un conflicto entre el bienestar general versus intereses individuales. Sin embargo, sus causas fundamentales fueron el cuestionamiento al rol distribuidor del Estado y de las atribuciones de José Melo, y la

\footnotetext{
${ }^{41}$ ANHISAN, Consejo de Defensa Fiscal a Intendente de Santiago. Santiago, 11 de mayo de 1909. Vol. 328, s/f.

42 BN, "Las aguas de los ríos Mapocho y Maipo. Presentación al Senado". El Diario llustrado. Santiago, 5 de febrero de 1910 , p. 3.
} 
vulneración de derechos de aguas adquiridos con anterioridad a la creación del cargo de fiscalizador de las aguas del río Mapocho.

La falta de precipitaciones en la segunda mitad de la década de 1900 agrietó las relaciones dentro de la Intendencia de Santiago y con otras instituciones estatales que repartían, o buscaban repartir, el recurso hídrico dentro de la provincia. En el período estudiado, los jueces de aguas -funcionarios provinciales dependientes de las intendencias- se encargaban de distribuir mercedes de aguas y dirimir conflictos de derechos entre particulares, a quienes la Intendencia de Santiago, primeramente, les requirió el aprovisionamiento hídrico de la ciudad. En julio de 1908 el gobierno provincial solicitó al juez de aguas del río Mapocho Darío Jofré, ante el limitado flujo del río, que sirviese "disponer lo conveniente a fin de que en lo sucesivo el Mapocho conduzca la cantidad de agua necesaria para el abastecimiento de la ciudad", sugiriendo el rateo proporcional de derechos, la distribución del agua por turnos y limitar el derecho de los dueños de fundos ${ }^{43}$. Meses más adelante, la Intendencia envió una nota al juez de aguas solicitando nuevamente la provisión de agua de la capital, particularmente de los barrios ulteriores del Mapocho, debido al bajo caudal del canal Santo Domingo ${ }^{44}$. Incluso hubo apoyo de la Intendencia de Santiago a la gestión de los jueces de aguas, como en una reunión celebrada en septiembre de 1908, en la que el Intendente Pablo Urzúa ofreció solicitar al Gobierno Central fuerzas de carabineros, previa petición de los jueces de aguas para procurar un mejor servicio de aguas corrientes para la ciudad ${ }^{45}$.

Sin embargo, a partir de fines de 1908 existieron cuestionamientos de la Intendencia de Santiago a la labor realizada por sus jueces de aguas. Dicha institución provincial ordenó al juez del río Mapocho que limitase el derecho de concesiones de aguas de los propietarios de fundos del oriente de la ciudad; no obstante, la Intendencia verificó que aquello no se había cumplido debidamente. El Intendente Pablo Urzúa informó esta situación al Ministerio de Industria el 21 de diciembre de 1908, junto con comunicar la conveniencia de designar a una persona que fiscalizase el reparto de aguas del río Mapocho, cargo que desempeñó José Santiago Melo. Por tanto, los cuestionamientos a la gestión de los jueces de aguas de Santiago fundamentaron la creación extraordinaria del Delegado Fiscal para el Mapocho. Un año más tarde, las críticas de la Intendencia de Santiago hacia sus jueces de aguas fueron más graves. Junto con acusar que el juez del río Mapocho hacía caso omiso a las indicaciones e instrucciones dadas por la institución provincial, la Intendencia avisó al Consejo de Defensa Fiscal la posesión de antecedentes "que le permitían formarse conciencia exacta de que dicho juez procedía con

\footnotetext{
${ }^{43}$ ANHISAN, Intendente de Santiago a Primer Alcalde de la I. Municipalidad de Santiago. Santiago, 20 de julio de 1908. Vol. 323, s/f.

${ }^{44}$ BN, "Provisión de agua". El Chileno. Santiago, 14 de diciembre de 1908, p. 2.

45 BN, "Las aguas de la ciudad. Reunión de autoridades locales". El Diario Ilustrado. Santiago, 29 de septiembre de 1908 , p. 5.
} 
toda arbitrariedad en el desempeño de sus delicadas funciones, haciendo el reparto de aguas a su real antojo y conveniencia" ${ }^{46}$. Seguidamente, el Intendente Pablo Urzúa alabó la designación del Delegado Fiscal José Santiago Melo, quien "dio muy pronto los resultados apetecidos, regularizándose en absoluto el servicio de aguas corrientes de la ciudad y concluyéndose con ello todos los reclamos y quejas que con razón constituían una verdadera alarma pública”" ${ }^{47}$.

A su vez, jueces de aguas de la Provincia de Santiago criticaron a la Intendencia y a su Repartidor de Aguas, a raíz de las atribuciones y funciones de José Santiago Melo. El malestar de los jueces ante las restricciones para desarrollar sus funciones fue demostrado en una comunicación enviada por el juez repartidor de las aguas del río Maipo a la intendencia, como respuesta a un oficio del Ministerio del Interior que ordenaba al Delegado Fiscal José Melo determinar la dotación de agua para abastecer Santiago. El juez reclamó que Melo no tenía facultades para alterar la distribución de las aguas de los canales matriculados en el río Maipo, ni para reducir las cuotas que a cada uno de ellos le pertenecía. Asimismo, la autoridad provincial protestó por la coacción sufrida por el Poder Ejecutivo, pues, auxiliado por la fuerza pública, alteró el reparto de las aguas del río y perjudicó a particulares con derechos hídricos ${ }^{48}$. En definitiva, el control del Gobierno Central sobre el caudal de los ríos de la Provincia de Santiago trajo consigo las críticas hasta de sus propios funcionarios.

Como fue expuesto en páginas anteriores, la Alcaldía de Santiago mostró preocupación por la escasez hídrica de la segunda mitad de la década de 1900. Una de sus iniciativas en 1908 fue reunirse con otras autoridades estatales y juntas de canalistas para evitar la interrupción del abastecimiento y dotar de herramientas técnicas y humanas a los jueces de aguas. A partir de tal año, el municipio buscó adoptar un rol más protagónico en la distribución hídrica de la ciudad. La estrategia trazada comenzó también con la crítica hacia los jueces de aguas de Santiago. En agosto de ese año, el prefecto de la policía de aseo de la ciudad escribió una nota a la alcaldía con dos aspectos claves: la existencia de una escasez hídrica que atentaba contra la salubridad de Santiago, y que el juez de aguas del Mapocho no había solicitado los elementos ofrecidos por la casa edilicia para dotar de mayor cantidad de agua a la ciudad. Por ello, el oficial solicitó al alcalde que ejecutase obras para aumentar la disponibilidad de agua para la ciudad, las cuales no habían sido hechas por el juez de aguas ${ }^{49}$. En base a lo expuesto, hubo semejanzas en los procesos de búsqueda del control del agua en la capital de Chile hechos por la Intendencia y la Alcaldía de Santiago, pues ambas persiguieron ese afán en 1908 y dirigieron sus críticas a la labor de los jueces de aguas de la provincia.

\footnotetext{
${ }^{46}$ ANHISAN, "Consulta derechos que corresponda Municipalidad, sobre reparto aguas Mapocho". Santiago, 6 de agosto de 1909. Vol. 340, s/f.

47 Ídem.

${ }^{48}$ ANHISAN, Santiago, 10 de julio de 1910. Vol. 351, s/f.

${ }^{49} \mathrm{BN}$, “La escasez de agua. La desidia de un empleado". El Diario Ilustrado. Santiago, 2 de agosto de 1908, p. 2.
} 
En 1908 la Municipalidad de Santiago repartió aguas del río Mapocho en el tramo que pasaba por la comuna. Un caso ilustrativo ocurrió en agosto de dicho año, cuando el alcalde Pablo Donoso distribuyó las aguas del río en tres partes para los sectores norte, centro y sur de la ciudad con auxilio de la fuerza pública. El motivo principal de la acción fue que los sectores centro y sur quedaron "pocos menos que a secas", ya que los vecinos del norte de Santiago, especialmente los dueños de molinos, obtuvieron gran parte de las aguas del río gracias a la distribución hecha por el juez de aguas del Mapocho ${ }^{50}$. Fue aquel funcionario quien protestó, ante el Cuarto Juzgado de la provincia de Santiago, la decisión del alcalde Donoso, junto con solicitar la exclusividad en la distribución de las aguas del Mapocho. Sin embargo, el tribunal respaldó el rol repartidor del alcalde Pablo Donoso, al fallar en contra de la petición del juez de aguas de dicho rí $^{51}$. En otras palabras, el poder judicial dio la razón a la Municipalidad en este caso contra la Intendencia de Santiago.

En vista al creciente protagonismo de la Municipalidad de Santiago en el devenir hídrico de su comuna, surge la cuestión relativa a cómo fue la relación entre ella y la Intendencia de Santiago, instituciones que buscaban controlar, en el mismo período, las aguas del río Mapocho. A modo de respuesta, se plantea que hubo un conflicto entre ambas instituciones manifestado en agosto de 1909, fecha en que ambas se adjudicaron el derecho exclusivo de vigilar y distribuir las aguas del río Mapocho que pasaban por Santiago. Por una parte, la Alcaldía reafirmó su derecho hídrico por "mercedes otorgadas desde tiempo inmemorial [...] siempre limitadas por las necesidades de la población". De acuerdo a la Corporación Municipal, esta potestad posibilitaba la vigilancia y distribución de sus aguas por parte del Inspector Delegado de la Municipalidad, Carlos Rivas. Esta autoridad dijo que sus únicos fines fueron asegurar la dotación de agua de la ciudad e impedir que fuese sacada por otros canales. El conflicto con la Intendencia de Santiago surgió por la amenaza de "prisión arbitraria" hacia el señor Rivas, hecha por el Delegado Fiscal de las aguas del Mapocho, José Melo. De ahí que el Municipalidad enviara una nota de protesta a la Intendencia por la actuación del señor Melo, acusando que él impedía el control de la alcaldía sobre marcos y tomas que eran bienes nacionales de uso público ${ }^{52}$.

La Intendencia de Santiago y su Delegado Fiscal José Melo defendieron sus labores sobre el río Mapocho y pusieron en duda el bienestar general de la ciudad que perseguía la Municipalidad capitalina. Melo expresó la imparcialidad con la que ejercía su trabajo y cuestionó, a su vez, la de Carlos Rivas, a quien acusó de favorecer a un vecino de apellido Manier y perjudicar a otros dos vecinos de apellidos Grau y Velásquez, por medio del refuerzo de la

\footnotetext{
${ }^{50} \mathrm{BN}$, “El agua del Mapocho. Conflicto de intereses”. El Diario llustrado. Santiago, 26 de agosto de 1908, p. 1. 51 Ídem.

52 ANHISAN, Primer Alcalde de Santiago a Intendente de la Provincia de Santiago. Santiago, 10 de agosto de 1909. Vol. 331, s/f.
} 
vigilancia de los puntos del Mapocho donde se surtían de agua. El Delegado Fiscal aseguró que Rivas desempeñaba sus labores acompañado del señor Manier y se servía de sus caballos, además de señalar que el Mayordomo Municipal frecuentaba la casa de Manier para consultar por su abastecimiento hídrico ${ }^{53}$. José Melo también criticó que el Inspector Delegado del municipio de Santiago sobrepasara los límites territoriales al desempeñar sus funciones, pues "ha llevado sus atribuciones a Providencia, que es donde están situados los puntos del río Mapocho materia de su reclamo"54; es decir, Rivas buscaba vigilar y distribuir las bocatomas que abastecían Santiago, pero estas se encontraban fuera de sus límites territoriales.

El conflicto por la legalidad del actuar de la Municipalidad y la Intendencia de Santiago fue dilucidado dentro del Estado, ya que el Consejo de Defensa Fiscal emitió un informe el 9 de septiembre de 1909 sobre la intervención de autoridades locales en el reparto de las aguas del río Mapocho. El Consejo estableció que la función repartidora efectuada por ambas instituciones era temporal y extraordinaria, ya que no había un juez de aguas en funciones y había un contexto de sequía que exigía adoptar medidas urgentes. Pese a lo anterior, la Municipalidad de Santiago no tenía facultad para repartir aguas del río Mapocho porque su curso atravesaba a varias municipalidades; así, resultaba inaplicable una ley de diciembre de 1891 que confiaba a las municipalidades el reparto de las aguas de un río o estero de uso público que corriese exclusivamente dentro del territorio municipal. Así, el Consejo de Defensa Fiscal autorizó al Intendente de Santiago a hacer cumplir las leyes y ordenanzas en época de escasez de aguas, así como a tomar medidas provisionales para asegurar la provisión hídrica de la población. Uno de sus argumentos fue jurídico. El artículo no 22 de la Ley de Régimen Interior facultaba a la Intendencia a desplegar dichas acciones en períodos de crisis hídrica. Mientras que los otros dos fueron de orden burocrático, ya que hubo un reconocimiento hecho a la Intendencia por haber solicitado al Gobierno Central una consulta sobre la legalidad de la intervención del río Mapocho por parte suya, y el Consejo de Defensa Fiscal destacó en su informe que el Ministerio de Industria y Obras Públicas autorizó la designación de José Melo para atender el reparto equitativo de las aguas del Mapocho hacia los particulares y la ciudad ${ }^{55}$.

El informe elaborado por el Consejo de Defensa Fiscal devela la idea central de este capítulo, referida a que la estrategia del Estado de controlar el caudal de los ríos de la Provincia de Santiago como respuesta a la sequía, evidenció tensiones y conflictos suscitados dentro de este. Algunas de sus causas fueron el creciente rol que buscaron adoptar distintas instituciones y autoridades, junto con la influencia de intereses particulares en la actuación de las reparticiones burocráticas. En base a esto último, es pertinente preguntarse: ¿qué relaciones hubo entre el

\footnotetext{
${ }^{53}$ ANHISAN, Intendente de Santiago a Primer Alcalde de Santiago. Santiago, 5 de agosto de 1909. Vol. 345, s/f.

54 Ídem.

55 ídem.
} 
Estado y particulares, en cuanto al aprovisionamiento hídrico de la Provincia de Santiago? ¿Cuál fue la relevancia de actores privados en la gestión hídrica de dicha zona?

\section{Incentivo estatal a la iniciativa privada: aprobación de la Ley no 2139 de Asociaciones de Canalistas.}

A raíz de la sequía de segunda mitad de la década de 1900, el Estado se planteó como objetivo prioritario la provisión segura de agua para la población. Ello fundamentó el mayor control de las aguas de los ríos de la Provincia de Santiago, lo que, paradójicamente, mostró conflictos entre algunas de sus instituciones. Aquella misión también justificó otra estrategia estatal que, en teoría, mitigaría los efectos de la reducción de agua disponible, que fue la entrega de la administración de las aguas de canales a particulares que se abasteciesen de un mismo afluente. Este objetivo se materializó con la promulgación de la ley número 2139 de Asociaciones de Canalistas en noviembre de 1908, cuyo proceso de discusión y los discursos de miembros de la elite política y económica demostrarían la conveniencia de que las sociedades de canalistas gestionasen sus derechos hídricos a plenitud.

La gestación, el trámite y la discusión de aspectos relativos a la ley de Asociaciones de Canalistas sugieren que hubo una clara unanimidad en aprobarla por parte del Poder Legislativo, dado el breve período que demoró su aprobación y los casi inexistentes cambios realizados al boceto inicial presentado por el Ejecutivo. El proyecto fue estudiado por una Comisión especial de Riego de la Cámara de Diputados el 6 de agosto de 1908, quien aprobó sus ideas e hizo correcciones solo a elementos de forma para aclarar mejor su contenido ${ }^{56}$. Ese mismo mes, el proyecto fue discutido en forma general por la Cámara de Diputados, pero no pudo ser aprobado por falta de quórum en la sala. El diputado Alejandro Huneeus, férreo defensor de este proyecto, consideró que "las asociaciones de canalistas han tropezado con todo género de dificultades a causa de no estar contemplada ni bien definida la situación jurídica ni comercial de las referidas asociaciones". Para solventar ese inconveniente legal, Huneeus propuso acelerar lo más posible la aprobación del proyecto sin evaluar sus aspectos específicos: "me parece, pues, que la discusión general no puede dar margen para observaciones extensas. En cuanto a la discusión particular, se trata de un asunto que ha sido ampliamente estudiado [...] y para no destruir la armonía en conjunto y la trabazón de sus disposiciones, creo que habría conveniencia en aprobar todos los artículos tales como están" 57.

El proyecto fue aprobado por la Cámara de Diputados el 15 de octubre de ese año, luego que el hemiciclo aprobara una moción de Alejandro Huneeus para poner todo el proyecto en

56 Congreso de la República de Chile, Sesión 36a ordinaria en 6 de agosto de 1908, p. 1072. www.bcn.cl/obtienearchivo?id=recursoslegales/10221.3/19102/1/C19080806_36.pdf

57 Congreso de la República de Chile, Sesión 37 ạ ordinaria en $28^{-3}$ de agosto de 1908, p. 1165. https://www.bcn.cl/obtienearchivo?id=recursoslegales/10221.3/22080/1/C19080829_38.pdf 
discusión general y particular a la vez. Su promulgación fue el 9 de noviembre de 1908 y su publicación el día 20 de ese mes. Desde la aprobación del proyecto por parte de la Comisión de Riego hasta su publicación transcurrieron solo cuatro meses, plazo de tiempo muy breve considerando que el Parlamento chileno demoraba incluso años en aprobar leyes durante fines del siglo XIX y comienzos del XX, prácticas valoradas como deficientes posteriormente ${ }^{58}$. Esto, junto con la no modificación del contenido del proyecto de ley por la Comisión de Riego y la Cámara de Diputados, sugieren que hubo un interés general del Poder Legislativo por dotar de personalidad jurídica a las asociaciones de canalistas para que se encargasen del reparto y administración de las aguas de los canales.

La ley núm. 2139 de Asociaciones de Canalistas determinó la posesión del agua del canal a los accionistas, la formación de directorios entre los asociados, el regador como unidad para determinar los derechos de agua, la constitución de los derechos de agua en escritura pública, la aplicación de multas y sanciones hacia miembros de las asociaciones, y condiciones de créditos, prendas y garantías para realizar trabajos extraordinarios, entre otros. Más relevante aún es que este cuerpo legal certificó el dominio de actores particulares sobre las aguas provenientes de los ríos. Su primer artículo decretó que las asociaciones formadas por dueños de canales se convertirían en personas jurídicas, con el fin de tomar el agua desde la matriz, repartirla entre sus accionistas y mantener en buen estado sus infraestructuras hídricas ${ }^{59}$; en otras palabras, legitimó el reparto y la administración privada de las aguas extraídas de las bocatomas de los ríos.

El control hídrico sobre los canales fue impartido por los directorios de las asociaciones. Según la citada ley, las sociedades de canalistas debían ser administradas por estos directorios, nombrados en las juntas de socios según los estatutos de cada asociación. Dentro de sus funciones se encontraron la formulación de los presupuestos de entradas y gastos ordinarios y extraordinarios, celebrar sesiones periódicas y exigir el cumplimiento de los acuerdos para todos los socios, y establecer sanciones e intereses ante cuotas impagas de los asociados. El control prácticamente absoluto de los canales por parte de las sociedades de canalistas quedó de manifiesto en el rol interventor de sus directorios. El artículo número 17 de la ley estipuló que "el directorio de cada asociación resolverá, con el carácter de árbitro arbitrador, todas las cuestiones que se susciten entre los accionistas, sobre derechos o repartición de aguas, y las que surjan entre los accionistas y la asociación. No habría lugar a implicancias ni recusaciones, ni a recursos de apelación o de casación"60. El directorio se convirtió, de facto, en un tribunal de primera instancia para resolver todo asunto, disputa o conflicto ocurridos dentro de los márgenes de los canales y sobre las aguas que transportaban dichos acueductos. Su carácter

\footnotetext{
${ }^{58}$ Millar, René. 1992. El parlamentarismo chileno y su crisis, Santiago, Ediciones Universidad Católica de Chile.

59 Ley 2139. Santiago, 9 de noviembre de 1908. www.leychile.cl/Navegar?idNorma=136414

60 Ídem.
} 
absoluto quedó consagrado con la imposibilidad de los implicados de apelar a sus dictámenes dentro de la sociedad, por lo que debían recurrir "en vía ordinaria, ante los Tribunales de Justicia, pidiendo se modifiquen con arreglo a la ley y a los contratos, pero este recurso no obstará a que las resoluciones del directorio se cumplan y surtan efecto" ${ }^{\prime 61}$.

De esta manera, los tribunales de justicia ordinarios se convirtieron en instancias de apelación a resoluciones ya vistas y resueltas previamente por los directorios de las sociedades de canalistas, y los conflictos de las aguas de canales se transformaron en disputas entre accionistas que debían resolverse internamente dentro de los márgenes de las asociaciones. Esta dinámica despótica fue avalada por el Estado, en cuanto el Gobierno de Pedro Montt presentó este proyecto de ley y el Congreso Nacional lo aprobó sin modificaciones en su contenido. En consecuencia, el Estado "dejó hacer" a los particulares fuera de los márgenes de los ríos, respuesta estatal en un contexto de sequía en el que, discursivamente, se reconocía una menor disponibilidad de agua y la necesidad de asegurar su provisión y mejorar su distribución.

La Sociedad Nacional de Agricultura (SNA) desempeñó un papel destacado en la aprobación del proyecto que reguló las asociaciones de canalistas. Su consejo directivo envió comunicaciones al Congreso Nacional para acelerar su promulgación, como el oficio leído en la Cámara de Diputados en agosto de 1908 que pidió "el pronto despacho del proyecto que reglamenta las asociaciones de canalistas" ${ }^{\prime 2}$. El consejo de la SNA argumentó que su aprobación "viene a llenar una necesidad urgente. El reconocimiento de estas asociaciones como personas jurídicas les confiere derechos que son indispensables para la prosperidad de ellas, entre otros el de contraer empréstitos para realizar obras de mejoramiento"63. La estabilidad y seguridad del desenvolvimiento de los accionistas de aguas, agrupados en sociedades, eran anhelos de la Sociedad Nacional de Agricultura, interesada en que los particulares ejerciesen sus derechos de aguas sin contratiempos para regar sus campos y aumentar su productividad agrícola. Una editorial de la SNA publicada en 1911, con motivo de la inauguración de obras hidráulicas para la asociación de los canales de Lo Espejo, La Calera, Santa Cruz y San Vicente, enfatizó que estos conglomerados podían constituirse legalmente con personalidad jurídica y efectuar mejoras a sus infraestructuras. Esta situación era distinta antes de la promulgación de la ley 2139 , al no haber una definición clara de los derechos y obligaciones de las asociaciones de canalistas, lo que implicó, según la Sociedad Nacional de Agricultura, que sus obras fuesen solo contingentes y provisorias ${ }^{64}$.

\footnotetext{
61 Ídem.

${ }^{62}$ Congreso de la República de Chile, Sesión 38a ordinaria en 29 de agosto de 1908, p. 1172. www.bcn.cl/obtienearchivo?id=recursoslegales/10221.3/22080/1/C19080829_38.pdf

63 BN, Sociedad Nacional de Agricultura. 1908. Boletín de la Sociedad Nacional de Agricultura, № 9, Vol. 39, p. 531.

${ }^{64}$ BN, Sociedad Nacional de Agricultura. 1911. Boletín de la Sociedad Nacional de Agricultura, № 12, Vol. 42, pp. 725-728.
} 
La SNA no solo alentó a la Cámara de Diputados para aprobar prontamente la ley 2139 y respaldó públicamente su aprobación que beneficiaría a accionistas de aguas y agricultores, sino que también participó en la creación del marco regulatorio de las sociedades de canalistas creadas gracias a dicho cuerpo legal. Si bien se desconocen aspectos referentes a su elaboración, fue informado públicamente en junio de 1910 que "la Sociedad Nacional de Agricultura remitió al Ministerio del ramo el reglamento al que han de sujetarse las asociaciones de canalistas, el que tendrá que aprobarse por dicho Ministerio [de Industria y Obras Públicas] ${ }^{\prime \prime 5}$. De esta manera, la Sociedad, cuyos miembros poseían derechos de aguas para regar sus cultivos y, por tanto, estaban agrupados en asociaciones de canalistas, reglamentaron el funcionamiento de dichas agrupaciones de accionistas con la venia del Estado. Esto comprueba que los asuntos relativos a las aguas de canales, propiedad de particulares, eran regulados por los mismos actores privados a través de ordenaciones internas respaldadas por el Estado.

El dominio de accionistas particulares sobre los canales de la Provincia de Santiago es un reflejo de la influencia de la Sociedad del Canal del Maipo en la creación de la ley de asociaciones de canalistas, ya que fue considerada como inspiración y ejemplo para la legalización de otros conglomerados de accionistas. El diputado Alejandro Huneeus reconoció la "situación especial" de dicha sociedad al haber sido registrada su personalidad jurídica, en contraste con otros grupos que debían sortear varias dificultades ${ }^{66}$. La Sociedad Nacional de Agricultura defendió la aprobación del proyecto de ley, argumentando que la Sociedad del Canal del Maipo, "institución análoga a [las sociedades que se buscaban legalizar], viene desde largos años prestando importantes servicios a sus asociados y es de esperar que las nuevas que se formen habrán de corresponder a la protección legislativa que ahora solicitan"67. El Ferrocarril, periódico de un grupo capitalista liderado por José Pedro Alessandri, dedicó tintas a la relevancia de la Sociedad Nacional de Agricultura, de la Sociedad del Canal del Maipo y de la ley 2139 sobre asociaciones de canalistas para el progreso de Chile y del sector agrario en particular. En una editorial de noviembre de 1910 sobre la irrigación del país en perspectiva histórica, el periódico señaló que "desde que se instaló la primera Sociedad de Agricultura en nuestro país [...] la irrigación de nuestros fértiles campos pasó a ser tópico favorito de las aspiraciones generales" ${ }^{68}$. Mientras que otra publicación hecha el mes siguiente remarcó que "el éxito alcanzado por las disposiciones del Canal del Maipo, que obedecen al criterio científico y económico", y "las garantías que ofrece la trascendental ley de Asociación de Canalistas [...] a

\footnotetext{
${ }^{65}$ BN, "Reglamento de canalistas". El Chileno. Santiago, 24 de junio de 1910, p. 4.

66 Congreso de la República de Chile, Sesión 37ạ ordinaria en 28 de agoto de 1908, p. 1165. www.bcn.cl/obtienearchivo?id=recursoslegales/10221.3/22080/1/C19080829_38.pdf

${ }^{67}$ BN, Sociedad Nacional de Agricultura. 1908. Boletín de la Sociedad Nacional de Agricultura, № 9, Vol. 39, p. 531.

${ }^{68} \mathrm{BN}$, "El gran problema de la irrigación de nuestros campos". El Ferrocarril. Santiago, 22 de noviembre de 1910, p. 1.
} 
la cual empiezan a acogerse los más importantes canales de la república", eran dos factores relevantes en el fomento del regadío en el país ${ }^{69}$.

El Estado, importantes gremios productivos de Chile y la prensa escrita validaron a la Sociedad del Canal del Maipo como un modelo pionero al cual debían ceñirse el resto de las asociaciones legalizadas a partir de 1908. Sin embargo, investigaciones recientes han analizado la gestación y desarrollo de dicha sociedad, cuestionando su éxito en la administración, el reparto y la resolución de conflictos. Los autores propusieron que la privatización del Canal del Maipo fue una respuesta política a los aguaceros que azotaron Santiago en $1827^{70}$; es decir, se aprovechó la emergencia de eventos naturales para modificar la gestión del agua, tal y como ocurrió con la ley 2139 sobre asociaciones de canalistas que fue promulgada como respuesta a la sequía que azotó Santiago entre 1906 y 1908. Proponen que la Sociedad del Maipo fue concebida como una burocracia agro-gerencial, basada en la definición de Palerm que aplica a conglomerados que generan conocimientos mercantiles del agua y cuyas existencias dependen del "dejar hacer" estatal"1. Esta tolerancia del Estado provocó que la Sociedad del Canal del Maipo controlase con total autoridad sus aguas, a través del establecimiento de normativas, la ejecución de medidas de gestión que alteraban el abastecimiento de terceros, la determinación de la legitimidad o no de los usos hídricos, y las resoluciones de conflictos entre sus miembros ${ }^{72}$. Por lo tanto, los autores concluyeron que la Asociación de Canalistas del Maipo se insertó en el marco de los procesos de acumulación por desposesión ocurridos en Chile, en cuanto buscó maximizar sus ganancias a través del sometimiento de los intereses locales en el control de las aguas, precarizando las relaciones en la red hidro-social de la que era parte ${ }^{73}$.

\footnotetext{
${ }^{69}$ BN, "Las mercedes de agua y fomento de las obras de regadío" El Ferrocarril. Santiago, 16 de diciembre de 1910, p. 1.

${ }^{70}$ Camus, Pablo, Elgueda, Guillermo y Muñoz, Enrique. 2019. "Irrigación y organización social en una sociedad en transición al capitalismo: el caso de la Asociación de Canalistas del Maipo en Chile (S.XIX), en HALAC, № 2, Vol. 9, pp. 95-121.

71 Palerm, Jacinta. 2015. "La utilidad de estudios de larga duración para el análisis del impacto del regadío sobre la organización social. El caso de las sociedades de drenaje y diques de Holanda llamados waterschappen”, en Papeles de Geografía, № 61, Murcia, pp. 60-76.

72 Camus, Elgueda y Muñoz. 2019. “Irrigación y organización social en una sociedad en transición al capitalismo".

73 Ídem.
} 
Santiago y sus alrededores: parte de la zona central de Chile regada por los acueductos de la Sociedad del Canal del Maipo, 1902.

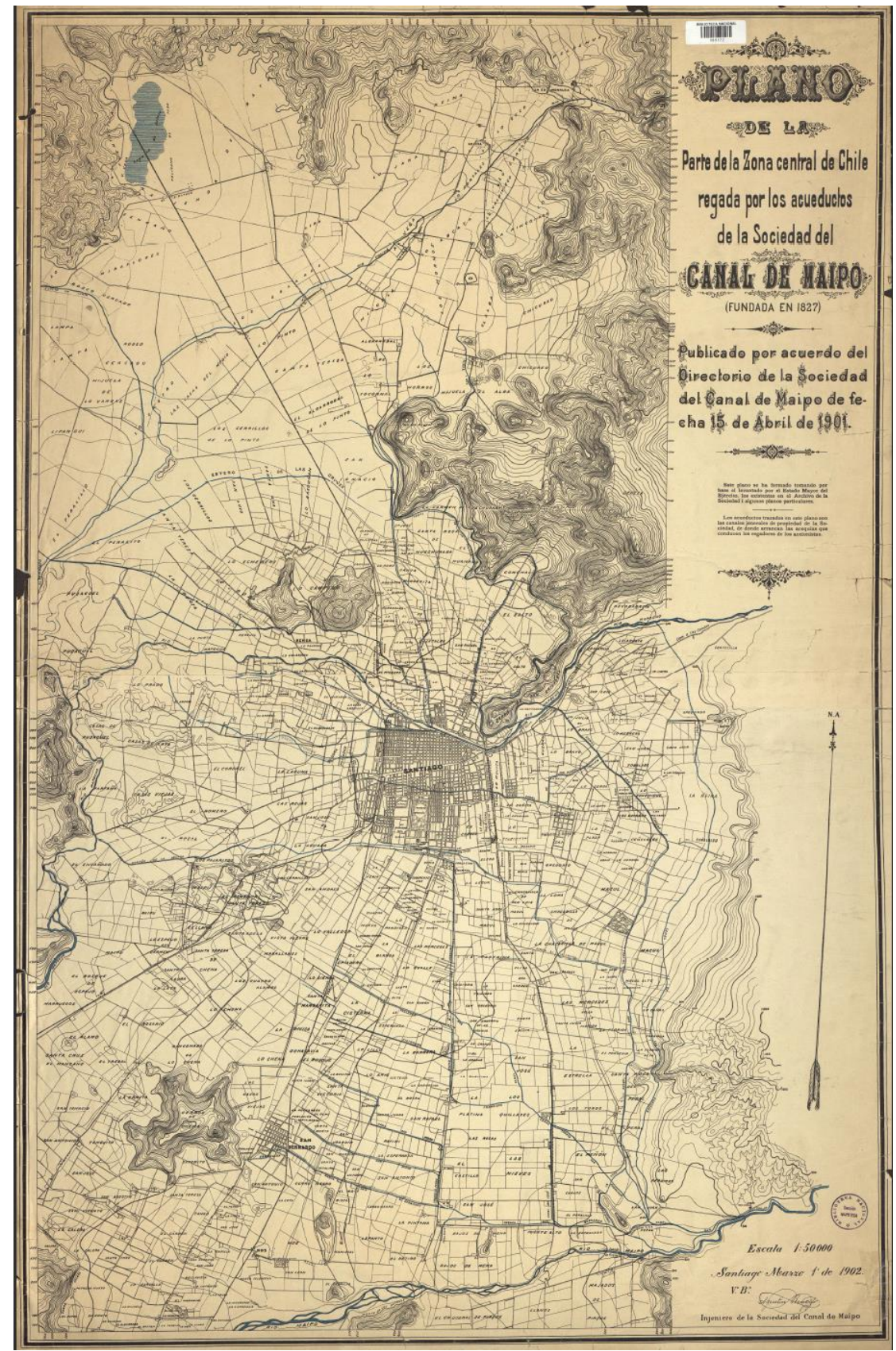

Fuente: Sociedad del Canal del Maipo. 1997. Sociedad del Canal del Maipo, 170 años, Santiago. 
En síntesis, la gestación de la ley 2139 como consecuencia de años de sequías y escasez de agua, la facultad dada a los directorios de las sociedades de canalistas de emitir resoluciones a los conflictos dentro de ellas, la actitud estatal de entregar el control de las aguas de canales a las asociaciones de canalistas, y el poder despótico de la Sociedad del Canal del Maipo, considerada por las elites económicas y políticas como un ejemplo de gestión hídrica, son factores que permiten sugerir que el manejo de los recursos naturales de nuestro país en los albores del siglo XX, habría operado bajo la lógica de la acumulación por desposesión.

\section{Consideraciones finales}

La mayor vigilancia y distribución del caudal de los ríos de la Provincia de Santiago, así como la legalización de las asociaciones de canalistas que administraban las aguas de los canales, fueron las dos estrategias estatales para, supuestamente, mitigar los efectos de la sequía de la zona metropolitana de Chile entre 1906 y 1908. El Estado se basó en la premisa que, al haber una menor cantidad de agua disponible, era necesario gestionarla de manera más estricta o eficiente. Sin embargo, fuentes de la época revelan que en 1910, año posterior a la implementación de dichas medidas, hubo nuevos episodios de escasez hídrica que afectaron a la provincia. Autoridades comunales y estatales recibieron las quejas de vecinos y propietarios que no contaban con agua en sus acequias ${ }^{74}$. El Estado, como respuesta a esta emergencia hídrica, depositó su confianza en actores privados para que atendiesen la provisión de agua. De acuerdo a información publicada por la Sociedad Nacional de Agricultura, la Sociedad del Maipo le propuso al Estado la expropiación de 200 regadores de agua del río Yeso para que dicha sociedad condujese ese caudal a través de su acueducto ${ }^{75}$. En una reunión de junio de 1910 en la que se encontraban el ministro del Interior, el intendente de Santiago, el director de Obras Públicas y el inspector de Obras Hidráulicas, acordaron que la Sociedad del Canal del Maipo condujese agua a través del canal San Carlos para el abastecimiento de Santiago ${ }^{76}$.

Las experiencias de 1908 y 1910 sugieren que el Estado no desplegó sus recursos económicos, técnicos y humanos para paliar la falta de agua para la ciudad, sino que entregó dicha responsabilidad a los grandes accionistas de aguas agrupados en sociedades de canalistas. Esta dinámica ha sido fundamentada con la idea que la escasez de agua ha sido una condición universal y natural, lo cual ha justificado, a su vez, la transacción del agua bajo parámetros de mercado. Es decir, si el recurso hídrico ha sido crecientemente escaso, debía requerir un

\footnotetext{
74 Primer Alcalde de Santiago a Intendente de Santiago. Santiago, 29 de octubre de 1910. ANHISAN, Vol. 355, s/f; "Remite oficio Alcalde Renca sobre escasez agua y pide regadores río Mapocho", Santiago, 18 de enero de 1910. ANHISAN, Vol. 357, s/f.

${ }^{75}$ BN, Sociedad Nacional de Agricultura. 1910. Boletín de la Sociedad Nacional de Agricultura, № 6, Vol. 41, pp. 324328.

${ }^{76}$ BN, “La escasez de agua”. El Diario Ilustrado. Santiago, 9 de junio de 1910, p. 2.
} 
manejo eficiente que solo el sector privado podría proveer ${ }^{77}$. El consenso unánime de las elites económicas y políticas en aprobar la ley no 2139 sobre asociaciones de canalistas estuvo fundado en la necesidad de los accionistas de agua de organizarse, con el fin de gestionar de manera segura y eficiente el recurso hídrico y realizar inversiones que trajeran retornos a largo plazo. El gran efecto de estas políticas de privatización del agua fue la reafirmación de la pérdida de la noción del agua como un bien común o público, pues las aguas provenientes de los ríos que traspasaban las bocatomas y llegaban a los canales, eran administradas soberanamente por las nacientes asociaciones de canalistas, sin que el Estado decidiera en cuanto a su reparto, administración y conflictos. En otras palabras, estos procesos de privatización redefinieron el agua como una mercancía más que como un bien común, y a sus usuarios como consumidores y accionistas en vez de miembros de una comunidad ${ }^{78}$.

La transacción del agua bajo parámetros de mercado provocó el aumento de la presión por obtenerla, al haber una demanda creciente que no pudo ser satisfecha con una oferta de similar cuantía. Los episodios recurrentes de inconvenientes para el abastecimiento hídrico de la ciudad, las denuncias a particulares que detenían el caudal del Mapocho, los robos de agua y la aparición de la violencia como forma de resolución de conflicto, sugieren que la escasez de agua vivida en la Provincia de Santiago en la segunda mitad de la década de 1900 fue un efecto de esta demanda creciente por el vital elemento, todo esto agravado por la disminución del volumen de precipitaciones entre 1906 y 1908. La acumulación por desposesión propuesta por David Harley dota de sentido las prácticas informales como el bloqueo de cauces y el robo de agua, así como la formación de asociaciones de canalistas. Todas ellas tuvieron como objetivo que particulares acaparasen más agua de la que poseían, a costa de los caudales utilizados por otros particulares y de los ríos que, en ese entonces, eran bienes de uso público. La ley sobre asociaciones de canalistas de 1908 y el Código de Aguas de Chile promulgado de 1981 son dos evidencias que permiten insinuar que la acumulación del agua por desposesión ha sido un proceso validado en inicios del siglo XX y profundizado a lo largo de este.

Para finalizar, es pertinente reflexionar acerca del Estado y su rol en la gestión del agua dentro del período estudiado. La gestión del aparato estatal ante la sequía hidrológica de 19061908, que engloba el actuar de las autoridades municipales, provinciales y nacionales, fue ambivalente. Por una parte, en su misión de vigilar los ríos y repartir sus caudales, el Estado evidenció tensiones y conflictos internos entre sus instituciones. Esto se debió a que la alcaldía e Intendencia de Santiago, en cuanto partes del aparataje estatal, no desplegaron esfuerzos coordinados ni complementarios para lograr el cometido de administrar las aguas de los ríos Mapocho y Maipo; por el contrario, cada una de estas reparticiones públicas actuó de manera

\footnotetext{
77 Bakker, Karen. 2003, “A political ecology”, p. 43.

${ }^{78}$ Ibíd., p. 39.
} 
aislada. Las deficiencias estatales descritas en el desarrollo de este estudio invitan a cuestionar el despliegue y la efectividad del Estado chileno decimonónico. Los temporales de lluvia que azotaron la Provincia de Santiago a fines del siglo XIX, probarían que el poder infraestructural del Estado fue menor al estimado por la historiografía, entendiendo este poder como el control estatal del territorio mediante la estandarización y demarcación de funcionarios burocráticos. Un ejemplo claro de este cuestionamiento fue la creación del cargo de delegado fiscal para el reparto de las aguas de Santiago, quien fue criticado por el alcalde de Santiago y los jueces de agua al desempeñar funciones ya hechas por ellos.

Mientras que, por otra parte, el Estado ejecutó exitosamente la legalización de las asociaciones de canalistas para que administrasen las aguas de los canales del país. La creación del proyecto de ley por parte del Gobierno Central, la modificación solo a aspectos menores de redacción hechos por la Comisión especial de Riego del Parlamento, su aprobación general y particular por parte de las Cámaras de Diputados y del Senado, y su rápida promulgación y publicación, son muestras del consenso político en torno a acentuar la privatización de la administración del agua. Si a eso sumamos los discursos favorables para aprobar la ley por parte de la prensa escrita y la Sociedad Nacional de Agricultura, junto con las misivas enviadas por esta última al Congreso para que fuese aprobada lo antes posible, este acuerdo político fue respaldado por actores que se verían beneficiados directamente, al poseer derechos de aguas e inversiones agrícolas cuantiosas y detentar el poder económico de la nación. La tramitación de la ley no 2.139 sobre asociaciones de canalistas prueba la idea de David Harvey que las privatizaciones de agua y otros bienes públicos son impulsadas desde el Estado a través de su poder $^{79}$, el cual es utilizado por la clase dominante para ejercer su hegemonía sobre el resto de la sociedad ${ }^{80}$. En consecuencia, conocer el funcionamiento, la gestión y los cambios en los sistemas hidro-sociales, es una aproximación para estudiar el poder político, los intereses económicos y el desenvolvimiento de la sociedad en un momento y espacio histórico determinado.

\footnotetext{
79 Harvey, David. 2003. El nuevo imperialismo.

${ }^{80}$ Gramsci, Antonio. 1975. Quaderni dal carcereen Cortes, Eugenio. 2014. "La hegemonia cultural hoy".
} 


\section{Fuentes y bibliografía}

\section{Fuentes}

Archivo Nacional Histórico.

- $\quad$ Fondo Intendencia de Santiago.

Hemeroteca de la Biblioteca Nacional (BN).

- $\quad$ El Chileno (1908 - 1910).

- La Prensa (1908).

- $\quad$ El Diario llustrado, Santiago (1908 - 1910).

- $\quad$ El Ferrocarril, Santiago (1910).

- Boletín de la Sociedad Nacional de Agricultura (1908, 1910 - 1912)

\section{Bibliografía}

Arthur, Maass y Anderson, Raymond. 1978. ... and the desert shall rejoice: Conflict, growth and justice in arid environments, Cambridge, MIT Press.

Bakker, Karen. 2003, “A political ecology of water privatization", en Studies in Political Economy, № 70, United Kingdom, pp. 35-58.

Bourdieu, Pierre. 1977. "Sobre el poder simbolico", en Gutiérrez, Alicia. 2000. Intelectuales, política y poder, Buenos Aires, UBA/ Eudeba, pp. 65-73.

Camus, Pablo, Elgueda, Guillermo y Muñoz, Enrique. 2019. “Irrigación y organización social en una sociedad en transición al capitalismo: el caso de la Asociación de Canalistas del Maipo en Chile (S.XIX)", en HALAC, № 2, Vol. 9, Anápolis, pp. 95-121.

Congreso de la República de Chile. 1908. Sesiones 36으 37a y 38o ordinarias, en agosto de 1908.

Davis, Mike. 2000. Late Victorian holocausts: El Niño famines and the making of the Third World, Londres. Verso Books.

García, Rolando. 1981. Nature pleads not guilty, Oxford, Pergamon Press.

Cortes, Eugenio. 2014. "La hegemonia cultural hoy: la hegemonía como método analítico en los estudios culturales", en Pensamiento Actual, № 22, Vol. 14, Costa Rica, pp. 13-27.

Harvey, David. 2003. El nuevo imperialismo, Madrid, Ediciones Akal.

Linton, Jamie. 2010. What is water? The history of a modern abstraction, Vancouver, UBC Press.

Linton, Jamie y Budds, Jessica. 2014. "The hydrosocial cicle: Defining and mobilizing a relationaldialectical approach to water", en Geoforum, № 57, Amsterdam, pp. 170-180.

Millar, René. 1992. El parlamentarismo chileno y su crisis, Santiago, Ediciones Universidad Católica de Chile.

Oficina Meteorológica de Chile. 1968. Estudio de las precipitaciones en Chile durante 429 años y la sequía del año 1968, Santiago. Disponible en:

http://www.bncatalogo.gob.cl/F/N7DDCRYIJC3ATIG9B4U1N1ALCTUPY2PKM3PF9ETK82DPBHT2VP28588? func=item-

global\&doc_library=BNC01\&doc_number=000371068\&year=\&volume=\&sub_library=

Palerm, Jacinta. 2015. "La utilidad de estudios de larga duración para el análisis del impacto del regadío sobre la organización social. El caso de las sociedades de drenaje y diques de Holanda llamados waterschappen", en Papeles de Geografía, № 61, Murcia, pp. 60-76.

Salazar, Gabriel. 2019. Historia del municipio y la soberanía comunal en Chile (1820-2016), Santiago, Universitaria. 
Sociedad del Canal del Maipo. 1997. Sociedad del Canal del Maipo, 170 años, Santiago, MP \& Vising Editorial.

Swyngedouw, Eric. 2009. "The political economy and political ecology of the hydro-social cycle", en Journal of contemporary water research \& education, № 142, Illinois, pp. 56-60.

Tvedt, Terje. 2010. "'Water systems', Environmental History and the Deconstruction of Nature", en White Horse Press, № 2, Vol. 15, Cambridgeshire, pp. 143-166.

Wittfogel, Karl. 1966. Despotismo Hidráulico, Madrid, Ediciones Guadarrama. 